\title{
GELIAT INDUSTRI SASTRA DI SEKOLAH: \\ PEMBELAJARAN SASTRA BERBASIS INDUSTRI KREATIF
}

\author{
Muttafaqur Rohmah \\ SMA Negeri 1 Banyuwangi \\ Email: muttafaqur45@gmail.com
}

\begin{abstract}
Abstrak
Kurangnya fasilitas sekolah, tidak tersedianya laboratorium sastra, dan kurangnya media dalam pembelajaran sastra menyebabkan melemahnya minat terhadap pembelajaran sastra, jalan pintas yang ditempuh oleh peserta didik adalah mencari fasilitas lain (media online) dalam menjawab permasalahan seputar pembelajaran sastra. Pencarian data (karya sastra) di media online bukan tanpa masalah, proses copy paste menumpulkan kreativitas peserta didik. Padahal, pembelajaran sastra di sekolah dapat menghasilkan produk-produk sastra (puisi, cerita pendek, cerita rakyat, dsb), yang sekaligus dapat menciptakan penulis-penulis baru. Perkembangan industri kreatif dalam bidang seni, termasuk di dalamnya adalah karya sastra, harus mampu memaksa guru dan peserta didik untuk berpacu dalam membuat karya sastra yang dapat dibukukan dan dinikmati oleh masyarakat sekolah.
\end{abstract}

Kata Kunci: sastra, industri kreatif, sekolah.

\begin{abstract}
Lack of school facilities, unavailability of literary laboratory, and the lack of media in teaching literature in the weakening interest in the study of literature, shortcuts taken by learners is looking for another facility (online media) to address the issues of literary study. Data search (literature) in online media is not without problems, copy and paste process dulls creativity of learners. In fact, the study of literature in schools can deliver the products literature (poetry, short stories, folklore, etc.), which can simultaneously create new writers. The development of creative industries in the fields of art, including the works of literature, to be able to force teachers and students to race in making literary works can be recorded and enjoyed by the public school
\end{abstract}

Keywords: literary, creative industry, school. 


\section{PENDAHULUAN}

Perjalanan sastra dan industri kreatif di Indonesia semakin menanjak semenjak banyak buku-buku sastra difilmkan, sebut saja mulai AADC, Ayat-ayat Cinta, Ketika Cinta Bertasbih yang booming, yang berawal dari karya sastra (novel). Nilai sastra dalam mainset masyarakat pada umumnya mulai bergeser, yakni tidak melulu "sastra berat" semacam novel-novel jadul yang ketika membacanya, dari segi bahasa, juga rasa yang tinggi. Masyarakat masa kini sedikit demi sedikit menilai karya sastra adalah karya-karya picisan. Sastra saat ini tak hanya berhadapan dengan sebongkah buku besar dan tebal, sastra kini bisa dinikmati dalam sebuah layar yang dapat disentuh dan digeser sesuka hati, sastra masuk ke dalam hati penikmatnya lewat media online, yang juga membebaskan para penulisnya untuk meletakkan karya sastra mereka di media online mana saja, sesuka hati. Tak pelak bermunculan pengarang-pengarang baru di media sosial seperti facebook, blog, tumbler, instagram, dsb.

Sedang pembelajaran sastra di sekolah entah bagaimana wujudnya berada dalam genggaman masing-masing pengajar yang memunyai kebebasan penuh untuk mengolah pembelajaran sastra di kelasnya dengan segala rupa. Dalam perjalanannya sastra di masa kini penuh dengan kebebasan dan jauh dari kesan syahdu juga indah, hal tersebut boleh dikatakan memengaruhi siswa dalam bersastra. Karya-karya sastra peserta didik comot sana comot sini dari internet. Kemudahan mengakses segala hal di internet menjadi penghambat kreativitas, tapi di sisi lain, kemunculan pengarang-pengarang baru di media online memicu semangat peserta didik untuk ikut-ikutan bersastra. Berkaca dari kejadiankejadian bersastra di media online, peserta didik bisa saja mengikuti jejak para pengarang-pengarang musiman. Sebut saja pengarang musim patah hati, pengarang musim jatuh cinta, dsb. Hal ini dapat dimanfaatkan guru untuk membukukan karya peserta didik. Sebagai wujud apresiasi guru dan sekolah juga salah satu penegasan bahwa menjadi seorang penulis bukanlah sebuah mimpi yang tidak pernah menjadi kenyataan.

\section{PEMBAHASAN}

32 | ISSN: 22477-5150, e-ISSN: 2549-2195 http://journal.unesa.ac.id/index.php/jpi 


\section{Pembelajaran Sastra di Sekolah}

Dalam lingkup personal atau mikro, pendidikan bertujuan mengembangkan potensi individu sesuai dengan kemampuannya ke arah pertumbuhannya menjadi manusia yang dapat bermasyarakat dengan baik. Berkait dengan ini, maka tugas guru adalah membina dan mengembangkan kecerdasan dan keterampilan, kejujuran, kedisiplinan, mengembangkan kreativitas, pengenalan atas kemampuan dan batas kemampuan sendiri, menanamkan nilai-nilai positif, dan mengembangkan kepribadian anak didik. Dengan kata lain, tujuan pendidikan dalam konteks mikro adalah pembinaan watak (Santoso dalam Widarmanto, 2013:141). Salah satu komponen pendidikan yang berkait dengan pembinaan watak adalah pengajaran sastra. Tujuan akhir pembelajaran sastra adalah memperkaya pengalaman siswa dan menjadikannya lebih tanggap terhadap peristiwa-peristiwa manusiawi, pengenalan dan rasa hormatnya terhadap tata nilai, baik konteks individual maupun sosial (Widarmanto, 2013:142). Pembelajaran sastra membawa siswa pada ranah produktif dan apresiatif. Sastra adalah sistem tanda karya seni yang bermediakan bahasa. Pembelajaran sastra menurut panduan penerapan KTSP perlu menekankan pada kenyataan bahwa sastra merupakan seni yang dapat diproduksi dan diapresiasi sehingga pembelajaran hendaknya bersifat produktif-apresiatif. Konsekuensinya, pengembangan materi pembelajaran, teknik, tujuan, dan arah pembelajaran harus menekankan pada kegiatan apresiatif.

Pengembangan kegiatan pembelajaran apresiatif merupakan usaha untuk membentuk pribadi imajinatif yaitu pribadi yang selalu menunjukkan hasil belajarnya melalui aktivitas mengeksplorasi ide-ide baru, menciptakan tata artistik baru, mewujudkan produk baru, membangun susunan baru, memecahkan masalah dengan cara-cara baru, dan merefleksikan kegiatan apresiasi dalam bentuk karya-karya yang unik. Pencipataan karya sastra merupakan keterampilan dan kecerdasan intelektual dan imajinatif. Karya sastra hadir untuk dibaca dan dinikmati, dimanfaatkan untuk mengembangkan wawasan kehidupan (Rahmad, 2001).

Sejalan dengan tiga hal tersebut dapat disimpulkan pembelajaran sastra adalah sebuah proses kreatif yang menghasilkan produk. Dalam menghasilkan sebuah produk atau karya sastra jalan berliku yang ditemui guru dan peserta didik. Sebab produk yang dihasikan hasruslah benar-benar murni buatan peserta 
didik, sedang pada kenyataannya penjiplakan atau plagiarisme menjamur di kalangan peserta didik. Kemudahan untuk mengakses informasi apapun termasuk karya sastra menjadikan produk tersebut bukan lagi produk unggulan. Tugas guru tentu saja memilah dan memilih produk tersebut. Seperti halnya yang diungkapkan Tjahjono bahwa keberhasilan pengajaran sastra sangat ditentukan oleh berhasil tidaknya komunikasi yang dibangun oleh guru dan siswanya. Keakraban guru dengan karya sastra, keakraban guru dengan perjalanan kreatif pengarang dan keakraban guru kepada siswanya akan menjadi jembatan yang kokoh untuk mempertemukan siswa dengan karya sastra (Widarmanto, 2014:143).

Permasalahan yang muncul berikutnya ketika menghasilkan produk (berupa produk karya sastra dalam bentuk tulis; puisi, cerita pendek, dsb) adalah sejauh mana mereka berkembang? Pertanyaan yang sering muncul; apakah mereka bisa? Seperti apa jadinya? Samakah seperti menulis sms? Status facebook? Apakah pola pikir mereka akan sama seperti ketika mereka menggambar gunung dengan lancip segitiga dan gambar jalan yang mengecil pada ujungnya? Akankan yang mereka hasilkan hanya itu-itu saja? (Rohmah, 2015:16). Sejauh mana peserta didik berkembang? Sejauh khayalan mereka? Tanpa batas yang jelas? Ataukah hanya pembelajaran yang menghasilkan persamaan pemikiran antara guru dan peserta didik saja? Akankah peserta didik sebagai wadah informasi dari guru tanpa pengembangan dari dirinya sendiri? Pertanyaan-pertanyaan tersebut dapat dijawab ketika antara guru dan siswa saling membuka diri dalam informasi apapun mengenai produk-produk sastra, produk sastra yang bagaimana? Apapun bentuknya. Baik yang vulgar, picisan, mendayu-dayu, dsb. Guru harus memberikan kesempatan kepada peserta didik untuk menceritakan dan mengetengahkan karya-karya sastra yang mungkin popular bahkan vulgar, namun guru harus bisa menjadikan dirinya sebagai jembatan yang menghubungkan antara nilai dan norma masyarakat yang ada dengan apa yang disajikan dalam karya sastra yang mungkin vulgar tersebut tanpa harus memberikan penghakiman. Pengenalan keberagaman sastra pada siswa akan menumbuhkan berbagai hal positif dalam diri siswa, antara lain (1) kebanggaan akan karya sastra Indonesia, (2) pemahaman yang lebih komplek terhadap berbagai corak estetika yang ada dalam sastra Indonesia, (3) 
pengenalan terhadap berbagai nilai, (4) menumbuhkan sikap demokratis terhadap berbagai keragaman nilai, (5) berkembangnya perasaan humanistik siswa, (6) tingkat apresiasi siswa terhadap sastra semakin tinggi, dan membangkitkan keinginan siswa untuk menulis (Widarmanto, 2014: 145).

Masalah terakhir dan utama pengajaran sastra di sekolah adalah kurangnya fasilitas sekolah yang mendukung proses belajar mengajar sastra. Laboratorium khusus bahasa dan sastra kurang diperhatikan disbanding laboratorium kimia, biologi, dan fisika, kurangnya apresiasi warga sekolah terhadap perlombaanperlombaan dalam ranah sastra juga memicu keengganan dan sikap masa bodoh dan tidak mau tahu terhadap isu-isu sastra dan keanekaragaman karya sastra, hal berikutnya adalah tidak adanya lahan pamer untuk karya sastra, tidak seperti lahan pamer pada pembelajaran biologi seperti binatang yang dibekukan yang diletakkan dengan apik di laboratorium, jenis-jenis larutan dalam kimia, dll, bukubuku pembelajaran sastra tidak sebanyak buku-buku pembelajaran lainnya, tidak hanya itu, bahkan pembelajaran sastra dalam kurikulum 2013 seolah disingkirkan. Seperti yang terlihat pada tabel berikut ini.

\begin{tabular}{|l|l|}
\hline \multicolumn{2}{|l|}{ Kompetensi Dasar Bahasa Indonesia Kelas X Kurikulum 2013} \\
\hline 3.1 & $\begin{array}{l}\text { Memahami struktur dan kaidah teks anekdot, laporan hasil } \\
\text { observasi, prosedur kompleks, dan negosiasi baik melalui } \\
\text { lisan maupun tulisan }\end{array}$ \\
\hline 3.2 & $\begin{array}{l}\text { Membandingkan teks anekdot, laporan hasil observasi, } \\
\text { prosedur kompleks, dan negosiasi baik melalui lisan } \\
\text { maupun tulisan }\end{array}$ \\
\hline 3.3 & $\begin{array}{l}\text { Menganalisis teks anekdot, laporan hasil observasi, } \\
\text { prosedur kompleks, dan negosiasi baik melalui lisan } \\
\text { maupun tulisan }\end{array}$ \\
\hline 3.4 & $\begin{array}{l}\text { Mengevaluasi teks anekdot, laporan hasil observasi, } \\
\text { prosedur kompleks, dan negosiasi berdasarkan kaidah- } \\
\text { kaidah teks baik melalui lisan maupun tulisan }\end{array}$ \\
\hline 4.1 & $\begin{array}{l}\text { Menginterpretasi makna teks anekdot, laporan hasil } \\
\text { observasi, prosedur kompleks, dan negosiasi baik secara } \\
\text { lisan maupun tulisan }\end{array}$ \\
\hline 4.2 & $\begin{array}{l}\text { Memproduksi teks anekdot, laporan hasil observasi, } \\
\text { prosedur kompleks, dan negosiasi yang koheren sesuai } \\
\text { dengan karakteristik teks yang akan dibuat baik secara }\end{array}$ \\
\hline
\end{tabular}




\begin{tabular}{|l|l|}
\hline & lisan maupun tulisan \\
\hline 4.3 & $\begin{array}{l}\text { Menyunting teks anekdot, laporan hasil observasi, } \\
\text { prosedur kompleks, dan negosiasi sesuai dengan struktur } \\
\text { dan kaidah teks baik secara lisan maupun tulisan }\end{array}$ \\
\hline 4.4 & $\begin{array}{l}\text { Mengabstraksi teks anekdot, laporan hasil observasi, } \\
\text { prosedur kompleks, dan negosiasi baik secara lisan } \\
\text { maupun tulisan }\end{array}$ \\
\hline 4.5 & $\begin{array}{l}\text { Mengonversi teks anekdot, laporan hasil observasi, } \\
\text { prosedur kompleks, dan negosiasi ke dalam bentuk yang } \\
\text { lain sesuai dengan struktur dan kaidah teks baik secara } \\
\text { lisan maupun tulisan }\end{array}$ \\
\hline
\end{tabular}

Dalam kurikulum 2013, selama satu tahun peserta didik akan mempelajari 4 jenis teks; teks laporan hasil observasi, teks eksposisi, teks prosedur kompleks, teks anekdot, teks negosiasi, hal tersebut berarti bahwa pembelajaran sastra hanya diberikan 1 kali dalam satu tahun kepada peserta didik, yakni hanya berupa teks anekdot saja, tidak ada pembelajaran secara khusus mengenai sastra dan produk-produk yang dihasilkan dalam bersastra. Padahal telah jelas pada UU Sistem Pendidikan Nasional Nomor 20 tahun 2003, tujuan pembelajaran sastra adalah untuk mewujudkan suasana dan proses pembelajaran agar peserta didik secara aktif mengembangkan potensi dirinya untuk memiliki kekuatan spiritual keagamaan, pengendalian diri, kepribadian, kecerdasan, akhlak mulia, serta keterampilan yang diperlukan dirinya, masyarakat, bangsa dan negara.

\section{Geliat Sastra di Sekolah: Menghidupkan Industri Sastra di Sekolah}

Telah diungkapkan sebelumnya bahwa dalam pembelajaran di sekolah, sastra adalah proses kreatif yang menghasilkan produk, jika kembali pada KTSP, pembelajaran sastra kelas $\mathrm{X}$ akan menghasilkan 2 produk pilihan, berupa puisi dan cerpen (dalam hal ini dapat berupa cerita rakyat, fabel, dsb pengembangannya merujuk pada kebijakan tiap-tiap guru). Seperti yang terbaca pada tabel berikut ini.

\begin{tabular}{|l|l|}
\hline Standar Kompetensi & Kompetensi Dasar \\
\hline $\begin{array}{l}\text { Mendengarkan } \\
\text { 5. Memahami puisi yang }\end{array}$ & $5.1 \quad$ Mengidentifikasi unsur-unsur bentuk \\
\hline
\end{tabular}

36 | ISSN: 22477-5150, e-ISSN: 2549-2195 http://journal.unesa.ac.id/index.php/jpi 


\begin{tabular}{|l|r|l|}
\hline \multicolumn{1}{|c|}{$\begin{array}{c}\text { disampaikan secara } \\
\text { langsung/tidak }\end{array}$} & $\begin{array}{l}\text { suatu puisi yang disampaikan secara } \\
\text { langsung ataupun melalui rekaman } \\
\text { Mengungkapkan isi suatu puisi yang } \\
\text { disampaikan secara langsung ataupun } \\
\text { melalui rekaman }\end{array}$ \\
\hline $\begin{array}{l}\text { Berbicara } \\
\text { 6. Membahas cerita } \\
\text { pendek melalui } \\
\text { kegiatan diskusi }\end{array}$ & 6.1 Mengemukakan hal-hal yang menarik \\
atau mengesankan dari cerita pendek \\
melalui kegiatan diskusi
\end{tabular}

http://journal.unesa.ac.id/index.php/jpi ISSN: 22477-5150, e-ISSN: 2549-2195 | 37 


\begin{tabular}{|c|c|}
\hline & $\begin{array}{l}\text { 11.2 } \\
\text { klasik } \\
\text { Menemukan nilai-nilai yang } \\
\text { terkandung di dalam sastra Melayu } \\
\text { klasik }\end{array}$ \\
\hline $\begin{array}{l}\text { Menulis } \\
\begin{array}{c}\text { 12. Mengungkapkan } \\
\text { pengalaman diri } \\
\text { sendiri dan orang lain } \\
\text { ke dalam cerpen }\end{array}\end{array}$ & 12.1 Menulis karangan berdasarkan \\
& $\begin{array}{l}\text { kehidupan diri sendiri dalam cerpen } \\
\text { (pelaku, peristiwa, latar) } \\
\text { Menulis karangan berdasarkan } \\
\text { pengalaman orang lain dalam cerpen } \\
\text { (pelaku, peristiwa, latar) }\end{array}$ \\
\hline
\end{tabular}

Pembelajaran sastra lebih beragam dan mengarah pada produk sastra yang dapat dihasilkan peserta didik. Merujuk pada KTSP, sebelum beranjak pada kurikulum 2013, guru dan peserta didik masih memunyai kesempatan untuk menghasilkan karya sastra. Penekanannya pada produk atau tulisan siswa, baik berupa puisi atau cerita pendek. Dari dua hal tersebut guru dan peserta didik dapat membuat sebuah kumpulan puisi atau kumpulan cerita pendek yang dapat dibukukan, dalam hal ini tugas guru adalah menyunting produk-produk sastra peserta didik agar bernilai dan bernas saat dilempar ke masyarakat, tugas penyunting membuat karya peserta didik menjadi lebih sempurna, tugas penyunting antara lain mengatur, memperbaiki, merevisi, mengubah isi, dan gaya naskah orang lain, serta menyesuaikannya dengan suatu pola yang dibakukan (Rifai, 2011:86), meskipun dalam kenyataannya istilah oleh siswa dari siswa untuk siswa lebih tepat digunakan, bagaimana tidak siswa (peserta didik) memproduksi, membayar biaya produksi, dan mendapat hasil produksi (berupa buku kumpulan puisi atau cerita pendek yang telah dibukukan).

Pertanyaan selanjutnya adalah bagaimana dengan proses penerbitan dan percetakan? Jika kesulitan menjangkau penerbit mayor atau penerbit nasional, proses tersebut bisa melalui penerbit-penerbit indie yang penerbitan dan percetakannya bisa dilakukan dengan sistem POD (print of demand) dan telah ber-ISBN (international series book number), mau tidak mau produk-produk sastra ini (fiksi populer) adalah bagian dari sistem industri yang pasti berkaitan dengan penerbitan, dapat dikatakan bahwa penerbit adalah pabrik fiksi populer (Dewojati, 2015: 51).

38 | ISSN: 22477-5150, e-ISSN: 2549-2195 http://journal.unesa.ac.id/index.php/jpi 


\section{SIMPULAN}

Pembelajaran sastra yang dianaktirikan di sekolah bukan halangan bagi guru dan peserta didik. Kemudahan dalam menciptakan produk (menerbitkan buku) melalui penerbit-penerbit indie menjadikan peserta didik penulis-penulis baru yang karyanya akan diperhitungkan dalam industri kreatif. Namun, yang perlu diperhatikan dengan sangat teliti adalah tingkat keaslian produk-produk yang dihasilkan peserta didik.

\section{DAFTAR RUJUKAN}

Dewojati, Cahyaningrum. 2015. Sastra Populer Indonesia. Yogyakarta: Gajah Mada University Press.

Kementrian Pendidikan dan Kebudayaan. 2013. Kompetensi dasar Sekolah Menengah Atas (SMA)/ Madrasah Aliyah (MA).

Rifai, Mien A. 2011. Pegangan Karya Ilmiah Indonesia- Gaya Penulisan, Penyuntingan, dan Penerbitan. Yogyakarta: Gajah Mada University Press.

Rohmah, Muttafaqur (Ed). 2015. Kembang Adiwiyata. Sidoarjo: Sarbikita Publishing.

Widarmanto, Tjahjono. 2013. Masa Depan Sastra (Mozaik Telaah dan Pengajaran Sastra). Sidoarjo: SatuKatabook @rt publisher.

Rahmad, Pembelajaran Sastra Indonesia di Sekolah: Antara Harapan dan Realita. 2014 makalah seminar pengajaran sastra di Fakultas Pendidikan Universitas Pakuan Bogor (online) http://gurupembaharu.com/home/pembelajaran-sastra-indonesia-disekolah-membandingkan-harapan-dan-realita-yang-dapatdiwujudkan/\# ftn4 (diakses tanggal 7 Mei 2016)

UU Sitem Pendidikan Nasioanal Nomor 20 Tahun 2003.

Pedoman Khusus KTSP Bahasa Indonesia (tanpa tahun). 